her bed, but the diffeulty in walking experienced before delivery still persisted, and gradually became worse, and she furtber complained of a great feeling of weakness and prostration of strength, also of aching pains shooting down the thighs, and pain in the loins, these being sometimes so severe as to cause her to fall. This condition persisted for two years, during which time she got into a low, nervous, debilitated state, losing appetite and flesh. She then again became pregnant, and the power of walking diminished so rapidly that at the end of the third month she was forced to keep the horizontal posture entirely. She remained in this condition for four montbs, when she was prematurely delivered of a still-born child at the seventh month. She attributes this premature birth to a very severe attack of diarrhoa which lasted several days. She was brought to the hospital a fortnight after this premature delivery. There was no history of syphilis.

On admission, the patient was quite unable to stand or walk, and even when lying down the thighs were flexed on the hip joints with a certain amount of difficulty, and the movement caused her great pain in the loins and hips. Pressing the two innominate bones together caused no pain, but when they were separated she experienced pain, though not of a very severe kind. There was also pain on pressure, and occasionally paroxysmal shooting pains, over the situation of the eleventh and twelfth ribs on both sides. The uterus was large and flabby from imperfect involution, but otherwise there was no uterine or ovarian affection. There was no diminution in the tactile sense, and no paralysis of the lower limbs, for these could be moved, though doing so caused pain.

She was ordered to be kept at rest in bed; a mixture of quinine and steel was prescribed, with a generous diet. She continued under the above treatment for a fortnight, but with no visible improvement as regards her power of lncomotion. The pains continued as bad as ever, and then, under the idea of it being some neurosis, she was ordered one-thirtieth of a grain of phosphorus in capsule twice a day. After taking this for three days the pains in the hips were somewhat better, but those over the lower ribs were still very bad. A blister was ordered over each of the eleventh and twelfth ribs, and the phosphorus to be taken three times daily. She continued under this treatment for a week, the result being great diminution in the pain in all parts, but there was still no improvement in the power of locomotion. On careful re-examination she com. plained of pain when pressure was made on the mons veneris just over the situation of the pubic symphysis, and when the innominate bones were pressed together and then separated, the hand, being pressed somewhat firmly over the pubic symphysis, detected a certain amount of movement, but of a very limited kind; but no depression could be made out. It was then thought that there might be some loosen. ing of the pelvic symphyses, and acting upon this idea a towel was bound tightly round the pelvis, as recommended by Trousseau. The result was that the patient expressed herself much freer from pain, and could walk up and down the ward with but slight difficulty, although with a tottering gait. A binder of strong coarse unbleached linen was made to lace round the pelvis, and she then got up every day. From this time her power of locomotion improved daily, and she was discharged a month afterwards, still wearing the bandage, and being able to walk with comparatively little difficulty, though she very soon became tired. At the end of February she was able to walk fairly well with the help of the binder, but she experienced a certain amount of pain and difficulty in getting upstairs, though she stated that this improved week by week. Her general bealth had greatly improved, and she had gained much in flesh.

\section{VICTORIA HOSPITAL FOR SICK CHILDREN, CHELSEA.}

LARGE HERNIA COMPLICATED WITH ARTIFICIAL ANUS AND UNDESCENDED TESTICLE; SUCCESSFUL OPERATION FOR RADICAL CURE.

(Under the care of Mr. Cowsti )

For the following notes we are indebted to $\mathrm{Mr}$. Walford, honse-surgeon.

George C-, aged four years, was admitted on July 18th, 1876 , with the following history from the medical man who
hHd previonsly attended him. "The hoy was seen for the first time three years ago; he had then a right inguinal hernia that had evidently been strangulated for some days There was great swelling and inflammation of the scrotum, that rapidly went on to suppuration and the formation of a fistulous opening into the gut. The whole of the fæcal matter piseed through that opening for a month; at the end of that time fæces began again to pass $\mathrm{p} r \mathrm{r}$ rectum, and the fistul us opening shortly closed. Now ther is ratber a large hernia, that is easily and completely reduced, but a truss fals to keep it up; and, moreover, the pressure of the pid frequently occasions so much irritation that it has to be discontinued altogether for a time."

On admission the boy was well nourished, and all the organs were healthy. There was a large inguinal hernia, ap parently indirect, on the right side. On removing the truss a small quantity of thin fluid with a fæcal odour escaped from the fistulous track. The hernia was about the siz of a man's fist, and was easily reduced. When replaced some of the tissue of the scrotum went up with it, being, as it were, invaginated. The right te-ticle was undescended. Ordered to remain in bed and take ordinary diet.

After three weeks there was no discharge; the hernia was reduced; a pad of lint was applied; while the boy was allowed ts walk about. The pad failed to keep the hernia up.

On Sept. 16th, the patient being under the influence of ether, Mr. Crowell made an incision about an inch and a half in length through the skin of the scrotum, and with a fer touches of the knife separated it from the adjacent cellular tissue. The skin was particularly adberent. The hernia was tben reduced, and the cellular tissue invaginated as far as the internal ring with the finger. The operator then transfired the inner pillar of the internal ring with a stout nedle, which, after the integuments had betn well drawn inwards, was protruded through the skin ahout one inch further from the median line. The needle was then withdruwn, hringing with it one end of a stout and pliable wire about twolve inches in length. The same process was re. pented with the external pillar. One end of the wire was n+x passed through the indurated base of the sac, and the two ends wre twisted together and drawn up close to the internal ring. A firm pad of lint was then placed between the upprr and lower apertures of exit of the wires, and the upper and lower ends of wire were firmly twisted together over the part. The after-treatment consisted of the application of cold wet lint to the wound, and the diet of milk and beef-tea. At 730 P.M. the temperature was $1002^{\circ}$, and seven drnns of tincture of opium were administered.

S pt 17rh.-8 A.Mr. : Has had a restless night. Abdomen cliublly tender; temperature $102 \cdot 2^{\circ}$. Repeat opium.9 P M : Trmperature $1018^{\circ}$. Patient has had some sleep.

$18 \mathrm{~h}$ - There is a small quantity of purulent discharge from the wound. Scrotum cedematous, particularly on the right side As the boy complained of pain the opium was repeattd. Wound dressed with Condy's fluid. Temp. 100".

20 h. - T m perature same. No pain; no tenderness of abdimen, which is somewhat tympanitic; bowels have not been relinved.

53 d - Eæres begin to pass through the wound. A simple enema yiven, obtained an evacuation per rectum. Tem. perature has gradually descended to $99^{\circ}$. $-8.20 \mathrm{P}$ Br. : Patient in a low state; pulse intermittent. Ordered two teaspoon. fals of hrardy every three hours.

25 th. - Has passed a bad night. Pain in neighbourhood of wire. The parts around have an angry appearance, Færes still pass through the wound.

$261 \mathrm{~h}$.-Und $\mathbf{r}$ chloroform the wire was cut and removed. Beneyth the pad was a firm knot of tissue. Another pad applied and firmly bandaged on.

Ot. 2nd. - Improving; no pain. Brandy stopped; an ego arid coine bread-and-butter allowed.

11 $\mathrm{h}$. - The bowels are relieved every two or three days by a simple enema. A smaller quantity of fæees passed by the incision.

$22 \cdot d-W i t h o u t$ any warning fæces began to pour from the wound in greater quantities than at any previnus time. (This change for the worse may possibly be accounted for by the fact that about an hour elapsed between the remoral of the dit ty and the application of a fresh pad.) Milk and beef-tea substituted for meat diet. 
25 th.-The wound continues to contract; the quantity of feces passed through it is less. A small hard lump, apparently the testis, was discovered in the right divisiun of the scrotum.

Jor. $26 \mathrm{rb}$-Nothing escaped through the fistula for the past eleven days until this morning, when a small quantity of thin froculent matter was seen. Euemata seldum required; par is continued. General health good; is taking low diet still.

Dec. 19ih.-All the frces are now passed per rectum. th ordinary truss applied, and the child allowed to move about.

Jan. 12th, 1877.-The child returned home wearing his truss. There is no sign whatever of any return of the hernia.

\section{NORTH STAFFORDSHIRE INFIRMARY.}

\section{EXTRAVASATION INTO PONS VAROLIT.}

(Under the care of Mr. Spanton.)

"IHE following case is interesting, in the first place, as being one of extravasation into the pons Varolii, a somewhat rare situation; secondly, as showing how extensive injuries may be produced in the deeper parts of the brain without any bruising of the surface being visible. One marked symptom in the case was the tight closure of the lips and the grinding of the teeth, possibly due to irritation either of the masticatory centre or of fibres passing to it through the pons. It was in all probability this closure of the mouth which caused the strong inspiratory efforts, by preventing the thorough oxygenation of the blood. It would, of course, be diffeult, if not impossible, to be certain whether the paralysis of the arm and face was due to the lesion in the left hemisphere or to that in the pons.

A strong healthy-looking man, apparently ab ut thirtyfive years of age, was admitted at $2.30 \mathrm{P} \mathrm{M}$., Decer ber $25 \mathrm{th}$, 1876. He bad been found at $11 \mathrm{~A}$. M. by a poiceman, 1 y $1 \mathrm{r}, \mathrm{g}$ in a state of unconsciousness, at the foot of a wall sbout seven feet bigh, which rormed the termination of the slope of a railway emhankment. From the footprints, it was seen that he hal walked dıwn the slope, probably thinking that it extended to the ground. It was a severe frost, and from the appearance of his clithes it was thought that he had lain out all night. He was at first taken to the policestation, but as be did not recover consciousness he was conreyed to the infirmary.

On admission his skin was very cold; pulse feeble. There \$as no sign of pain when the skin was piuched. Slight reflux movement on touching conjunctivæ. Eyes closed, rrspiration natural. Left pupil dilated and inactive; right natural. The only mark of violence was a bruise on left sbin. Hot bottles were applied, and a powder consisting of calnmel and jalap was administered. After a few bours a profuse perspiration broke out; the pulse became strong and regular, 70 . The breathing was entirely nasal, the lips heing tigbtly closed.

Dec. $26 \mathrm{rb}$. - At 5 a.M. be became very restless, tossing about, trying to throw off the $b$-dclothes and to get up, grinding his teeth at intervals, and screwing up the corver of the blanket with grat force. It was noticed that be used the right arm much more than the left. The eyes and mouth were closed during the whole time, and the skin was perspiring profusely.-10 A $\mathbf{m}$ : Bowels had acted twice treely. Much quieter. Respiration 40, laboured, the mecessary muscles being brought into play. Made a slight effort to withdraw the arm when pinched; gave no otb+r s'gn of pain.-2 $P$ M.; Working right arm about vinlently, stretches it out at full length, and moves it about as if feeling for something in the air ; if anything is put in bis hand he works it up and down violentiy as if using a bammer ; then he moves the same hand across the bedclothes as if clearing something away, and commences working again. Right eye partially open; ptosis of left. Still breathing through the nose, and it was noticed that the left ala was drawn in during inspiration, and the left angle of the mouth pnffed out in expiration. Bowels acted again. Perspiration profuse. Ice was applied to bead. Was pretty quiet the remainder of the day. Bowels acted again in the evening.

27 th.-Passed a quiet night, but at 8 A.M. became very violent, endeavouring to throw off the bedclothes and to get up.-10 A M : Quieter; pulse much weaker; respiration very laboured; twitchings of right arm. -7 P.Mr. : Still perspiring profusely; pulse weak; surdes forming on lips. 'Inere was no change in the symptoms until 1130 P.M., when the respitation became much slower, and he died at 12 o'clock. Owing to the patient's extreme restlessness, the temperature conld not be taken.

Autops $y$, fourteen hours after death.-No marks of violence on the head. A large amount of arachnoid and cerebrospinal fluid; pia mater and its choroid plexuses intensely congested. In the substance of the left frontal lobe a cavity, the size of a pea, filled with recent clot; extending forwards from this was a line of punctiform extravasations reaching to the anterior border of the brain. In the anterior part of the pons Varolii, and in the median line, was a similar cavity three-eightbs of an inch in diameter; this was surrounded by a circle of punctiform extravasations. Except that the brain-substance was intensely congested throngh. out, there was nothing else abnormal found. There was no fracture of the cranium. Other organs all healthy.

\section{NORTHERN HOSPITAL, LIVERPOOL.} CASE OF SCIRRHUS OF PROSTATE.

\section{(Under the care of Dr. Dickinson.)}

Primary scirruus of the prostate is so rare that the only other case with which we are acquainted was recorded by Mr. Adams in The Lancet, 1853, vol. i., p. 394. Some have even denied its existence, but the evidence of the occurrence of this condition cannot fairly be impugned. When cancer commences in the prostate, it is almost invariably encephaloid in character. Last year Mr. Butlin showed at the Pathological Society (see THe Lancer, 1876, vol. ii., p. 574) a specimen of primary scirrhus of the bladder, but in this case the prostate was almost entirely unaffected. The subjoined notes of this case, for which we are indebted to Mr. A. Craigmile, M.B., house-physician, will therefore be read with great interest.

G. B—, forty-seven years of age, a sailor, was admitted into the medical wards on O t. $20 \mathrm{tb}, 1876$, suffering from chronic rhenmatism. The pains in the juints soon passsd off, but as he remained very weak, a more careful examina. tion was made, and he then stated for the first time that he had pain and diffeulty in passing water. He had had gonorrbcea a year before, followed by stricture, for which he had been treated by instruments. The perineum was hard and cartilaginous, and there were two fistulous openings there. The glands in both groins were considerably enlarged, especially on the left side, and all were of a stony hardness. On examination per rectum, a hardened mass was felt, corresponding in size and shape to an enlarged prostate, and so bard as at once to suggest scirrbus, especially when associated with such glands. No catheter could be introduced bejond the stricture, but as morphia suppositories were found to give him ease in making water and freedom from pain, no further attem was made. The other signs were those of persistent cystitis, and occasionally he paseed blood. He got gradually weaker, and the cancerous cachexia became more marked. He died on the 12 th January, 1877.

The post-mortem appearances were the following:-The tissues at the base and sides of the bladder were all matted together and thickened. The prostate was about the size of a horse-cbesnut, and when cut into had all the appearances of scirrhus. There were three glands lying along the right iliac vessels much enlarged and hardened. The bladder showed well-marked sigus of cystitis, both ureters were greatly dilated and thickened, and the kidneys were undergoing atrophy from the backward pressure of the urine; but all these changes seem to have been due to the stricture rather tban to the disease of the prostate, since the prostatic portion of the urethra was of normal size, and the tumour did not seem to obstruct tbe outflow of urine. There was no appearance of cancer elsewhere, nor ang other noteworthy change in any of the oigans. Microscopic examination showed great dilatation of the tubes of the gland, with large collections of cells in tbem, as in ordinary glandular carcinoma, but there was exceedingly little infil- 